\title{
VIBRATION ANALYSIS OF CENTRIFUGAL PUMP WITH VARIABLE SPEED DRIVES
}

Sobhy, M. Ghoneam, Professor, Department of Production \& Design Engineering, Faculty of Engineering, Menoufia University, Ghoneam2200@yahoo.com

Samir, M. Abdel-Rahman, Associate Professor, Mechanical \& Electrical Research Institute, National Water Research Center, samir4@yahoo.com

Dalia, M.El-Gazzar,Researcher Assistant, Mechanical \& Electrical Research Institute, National Water Research Center, dalia_engdalia@yahoo.com

(Received April 2, 2011 Accepted April 21, 2011)

Variable speed drives (VSD) improve operation and performance of pumping system and allowing them to operate efficiently, match fluctuations in the water demand and hence saving energy over the required range of field operation. Variation of speed may considerably lead to coinciding of stationary speed with the critical speed. For VSD applications, the excitation frequencies become variable and the likelihood of encountering a resonance condition within the continuous operating speed range is greatly increased. Vibration tests were done to obtain the optimum Dynamic performance and its sensitivity due to speed variation. The present work was done on a test rig of a centrifugal pump unit with a variable speed drive. Forced vibration measurements were done at different operating speed ranged from $25 \mathrm{~Hz}$ to $50 \mathrm{~Hz}$ to determine vibration levels and exciting frequencies. Experimental modal testing was done at different conditions to simulate the design and installation cases. Operational modal analysis is done to simulate the actual operating conditions. Dangerous frequencies are well determined to avoid operation at resonance. Finite element model was done using ANSYS software to obtain the dynamic characteristics of the pump model analytically.

KEYWORDS: variable speed pumps, vibration analysis, modal analysis, resonance

\section{INTRODUCTION}

In most of water pumping stations, the speed of the pumping system is approximately constant with controllable flow rate to match the load demand. This water load demand is fulfilled by the traditional control methods such as throttling valves or bypass techniques to change the operating condition in the pumping system by increasing the system's backpressure or resistance of flow. This increase in pressure head shifts the pump's operating point to the left along its performance curve, and, typically, away from its best efficiency point. It is confirmed however, that these methods rise energy losses and hence bad efficiency performance over the range of operation [1]. It should be admitted that a variety of approaches can be considered to eliminate the traditional 
control losses and reduce the electrical energy consumption of water pumps. It is believed now that the most appropriate and most economic way for improving the water pump performance is the Variable Speed Drives (VSDs) [2]. Pumping units when driven by (VSDs), will have a flexible adjustment and monitoring of pressure and flow over a very wide range of operation. In addition the VSD will improve the performance of pumping unit and allow the pump to operate as near as possible to its maximum efficiency and hence saving energy over the required range of field operation. (VSDs) adjust motor speeds driving the pump to mach fluctuations in flow. In addition to energy savings, (VSDs) offer precise speed control and a soft-starting capability. Each control technique of course has its merits and demerits, so (VSDs) also have some potential drawbacks which can be avoided with appropriate design and application. Resonance problem is the most seriously drawback of the (VSDs) [3]. It can cause excessive vibration levels, which in turn are potentially harmful to equipment and environment. For (VSDs) applications, the excitation frequencies become variable and the likelihood of encountering a resonance condition within the continuous operating speed range is greatly increased from a variety of sources they may not have been excited by a constant speed drive [4]. The risk of the rotating element encountering a lateral critical speed increases when using (VSDs) [5]. However, vibration level increases with increasing speed of (VSDs) and amplitude of vibration increases greatly with increasing excitation forces. At normal operating condition, vibration level increased $3.8 \%$ by increasing running speed $66 \%$ [6]. It is known that varying speed of the pump affects head, discharge and power according to the affinity law relationships:

- Flow rate $\alpha$ speed $: \mathrm{Q} \alpha \mathrm{N}$

- Head $\alpha$ (speed $)^{2} \quad: \mathrm{H} \alpha \mathrm{N}^{2}$

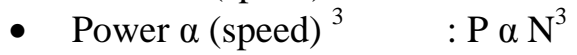

In centrifugal pump applications with no static lift, system power requirements vary with the cube of the pump speed. Small decreases in speed or flow rate can significantly reduce the used energy. For example, reducing the speed (flow) by $20 \%$ can reduce input power requirements by approximately 50\% [7]. The objective of this research is to obtain the optimum dynamic behavior and its sensitivity due to speed variation of the variable speed pumping unit. The present work was done on a test rig of a centrifugal pump unit with variable speed drive in the hydraulic lab of Mechanical \& Electrical Research Institute (MERI) .

\section{RESEARCH METHODOLOGY AND FACILITIES}

The test rig consists of a centrifugal pump used for irrigation purposes in the hydraulic lab of Mechanical \&Electrical Research Institute (MERI). The pump is of type Epara with power of $7.5 \mathrm{Hp}, 9 \mathrm{~A}, 3000 \mathrm{rpm}$, flow rate of $36 \mathrm{~m} / \mathrm{hr}$, and head of $7.5 \mathrm{~m}$ connected with variable speed motor. The pumping system consists of motor, pump, suction, and delivery pipelines.

Tests were done to evaluate dynamic performance of the pump unit. Forced vibration test is done to determine vibration levels and exciting frequencies using a dual channel (01dB Movipack analyzer) and a machine monitoring software package (eDiag) for evaluating dynamic running condition of the pump unit. 
Experimental modal tests were conducted using a spectrum analyzer $(\mathrm{B} \& \mathrm{~K}$ pulse 3560 hardware module 5 channels), Impact hammer to excite the pump unit with an impulse, accelerometer, and modal analysis software package (Modal Test Consultant - Type 7753 ). The modal testing facility is capable of determining the inherent dynamic characteristics of the pump unit including natural frequencies, damping factors, and mode shapes. Experimental modal analyses were done on the pump unit in two boundary and supporting conditions to simulate the design and installation conditions.

Operational modal analysis was conducted using LMS Test. Lab. Software with the (B\&K pulse 3560 hardware module 5 channels) analyzer. The system is capable of determining natural frequencies, damping factors, and mode shapes which are important in evaluating the dynamic behavior of the system. Configuration patterns of the system at the resonant frequencies and the operating conditions were defined. The natural frequencies of the pumping system were defined and when the exciting frequency approaches the natural frequency of the test object, the vibration level at the resonance are rapidly approaches a sharp maximum value. The pumping system and all facilities are shown in Fig. 1.

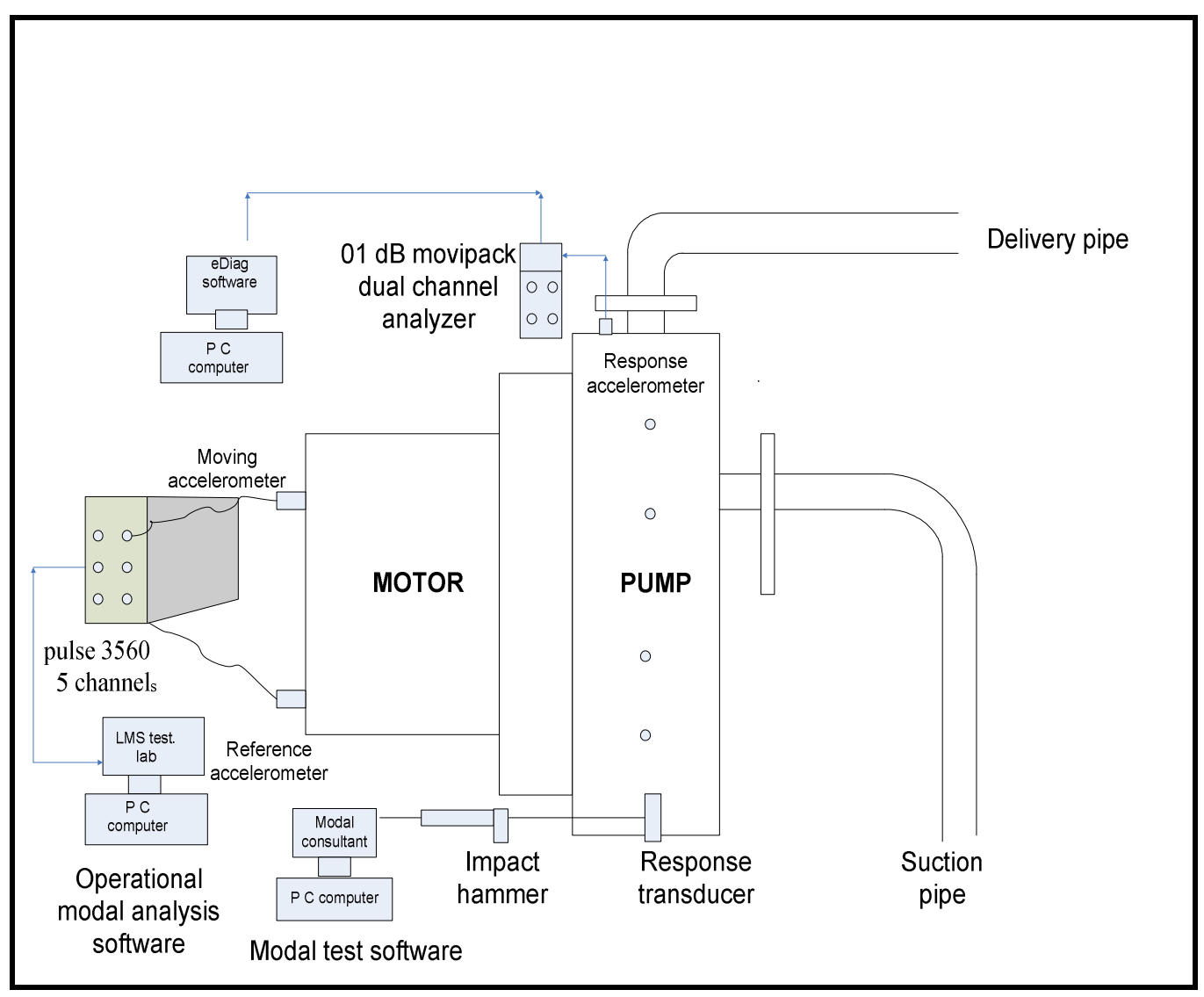

Fig. 1 Test facilities 


\section{FORCED VIBRATION ANALYSIS}

Forced vibration analysis was done on the variable speed centrifugal pump unit at different speeds in the range $(25,30,35,40,45$, and $50 \mathrm{~Hz})$ to specify the sources of vibration and define the exciting operational frequencies at different locations and different boundary conditions. The measurement location were done on the parts of the pumping unit including the motor and the pump at 8 locations in the axial, vertical, and radial directions as shown in Fig. 2. The measured parameters at every location are simple spectrum vibration velocity (FFT) in a frequency range from $2 \mathrm{~Hz}$ to $1 \mathrm{kHz}$ and overall vibration velocity $10 \mathrm{~Hz} 2 \mathrm{kHz}$. The signals from the accelerometers are directly fed into the $01 \mathrm{~dB}$ movipack analyzer which possesses an internal signal conditioning system comprising filters, integrators, amplifiers, etc. The signals are then transferred to the PC via USB connection to the eDiag software for signal analysis.

All these measurements were taken according to the ISO 1-10861 where the root mean square (RMS) was measured for all parameters because it is the most accommodate one for machine diagnosing where it expresses for the energy consumption due to vibration. It also takes the time history of vibrations [8]. The measurement locations are as follows:

- Point (1) motor non drive end in the radial direction.

- Point (2) motor non drive end in the vertical direction.

- Point (3) motor drive end in the radial direction.

- Point (4) motor drive end in the vertical direction.

- Point (5) pump drive end in the radial direction.

- Point (6) pump drive end in the axial direction.

- Point (7) pump drive end in the vertical direction.

- Point (8) pump non drive end in the horizontal direction.

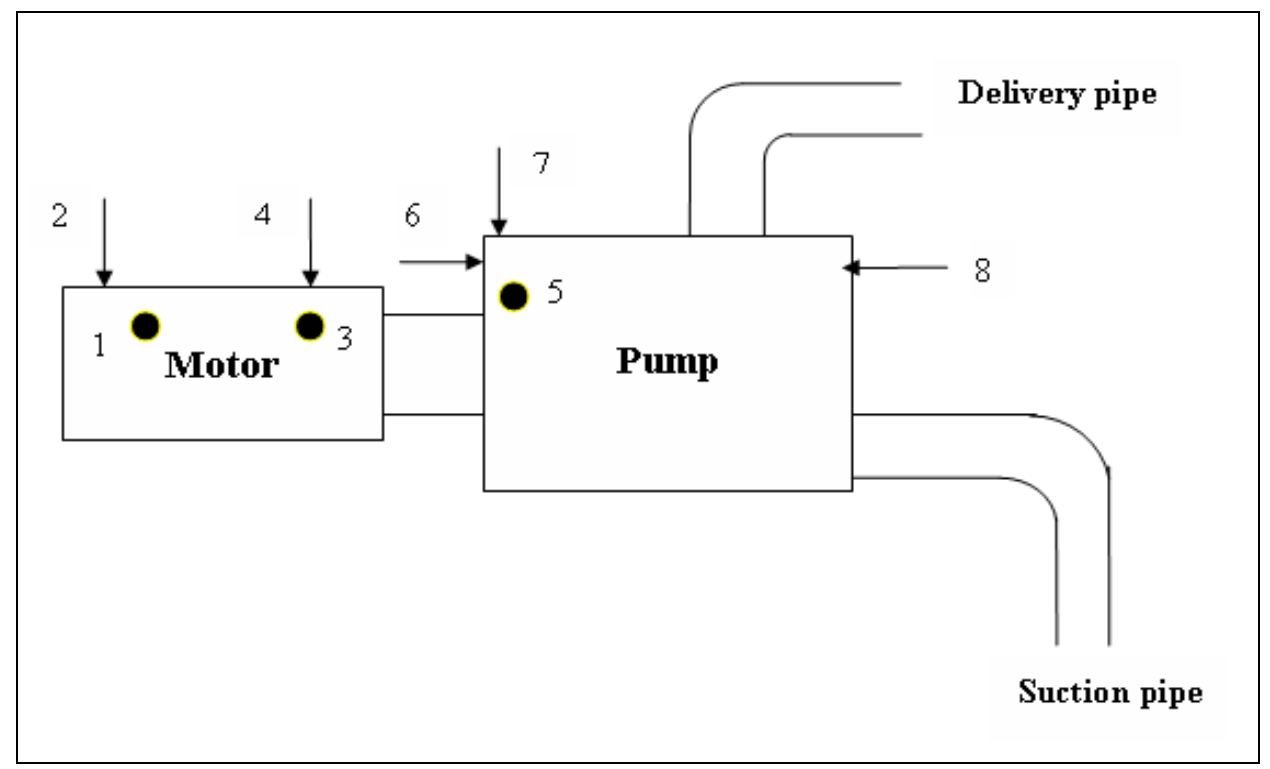

Fig. 2 Locations of vibration measurements 
The measurements showed that the maximum overall vibration level measured was reached $1.58 \mathrm{~mm} / \mathrm{s}$ on the motor and $1.28 \mathrm{~mm} / \mathrm{s}$ on the pump at running speed 50 $\mathrm{Hz}, 1.1 \mathrm{~mm} / \mathrm{s}$ on the motor and $1.06 \mathrm{~mm} / \mathrm{s}$ on the pump at running speed $45 \mathrm{~Hz}, 0.815$ $\mathrm{mm} / \mathrm{s}$ on the motor and $0.646 \mathrm{~mm} / \mathrm{s}$ on the pump at running speed $40 \mathrm{~Hz}, 0.646 \mathrm{~mm} / \mathrm{s}$ on the motor and $0.594 \mathrm{~mm} / \mathrm{s}$ on the pump at running speed $35 \mathrm{~Hz}$, and $0.393 \mathrm{~mm} / \mathrm{s}$ on the motor and $0.50 \mathrm{~mm} / \mathrm{s}$ on the pump at running speed $25 \mathrm{~Hz}$.

Vibration levels measured are good and safe according to ISO 1-10861 at all tests speeds except at resonance speed frequency $(30 \mathrm{~Hz})$, the overall vibration level reached value $2.91 \mathrm{~mm} / \mathrm{s}$ while the spectra shows that the vibration amplitude reached a value of $3.07 \mathrm{~mm} / \mathrm{s}$ at $30 \mathrm{~Hz}$ as shown in Fig. 3 and this value are dangerous and not permissible. The results proved that operation at resonant frequency generates dangerous vibration level. The results showed that vibration level increases slightly and smoothly with increasing running speed as excitation frequencies may be excited at higher speeds as shown in Fig. 4. The results indicated the importance of defining resonant frequencies firstly to avoid operation at these speeds or modifying structural properties to change resonant frequency through modal analysis.

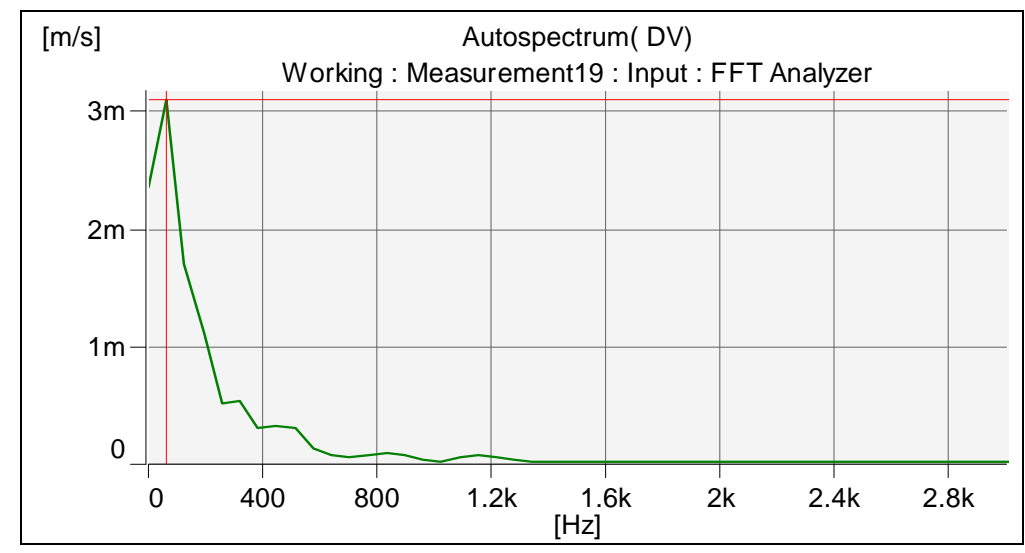

Fig. 3 Vibration spectrum measured at speed $30 \mathrm{~Hz}$



Fig. 4 Vibration level measured at different speeds on pump 


\section{EXPERIMENTAL MODAL ANALYSIS}

Modal analysis is a process whereby we describe a structure in terms of its natural characteristics which are the frequency, damping, and mode shapes which are called the dynamic properties. These properties are used to form the model of the dynamic behavior of structure system. Modal analysis is based on the fact that the response of a linear dynamic system can be expressed as the linear combination of a set of a simple harmonic motion called the natural modes of vibration.

Modal testing measurements were done on the whole pumping system at different boundary conditions at the laboratory. Different tests were done using different excitation and response locations to get reliable and applicable data. Experimental modal analysis was done at different phases of the pumping system representing design and installation stages. Modal testing was done by impacting the structure with the hammer to excite the system at fixed location and moving the response accelerometer around the whole structure at 47 locations as shown in Fig. 5.

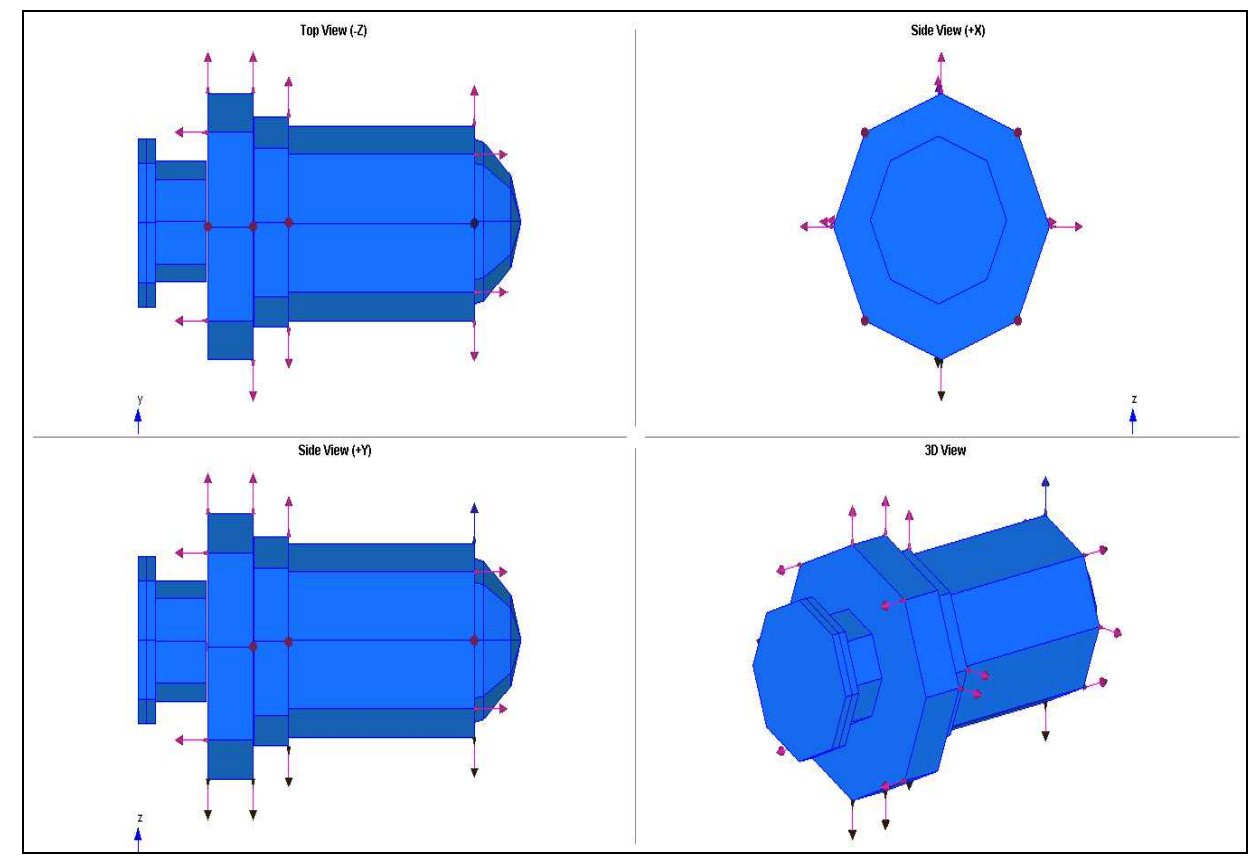

Fig. 5 Top and side views of the pumping system showing measurement locations

The experimental modal analysis was done on the pump unit in two boundary and supporting conditions to simulate the design and installation cases conditions. The pumping unit was first free support in air, and second was grounded support with pipe lines in water. Testing the structure in free condition determines the rigid body modes and thus the mass and inertia properties and it is recommended to always test structures in a freely supported condition. Also, testing the pump when it was grounded support in water with the pipe lines is to simulate the actual operation and installing conditions. Frequency Response Functions (FRFs) were measured for the pump unit free support in air, and for grounded support in water are shown in Fig.6 and 7. 




Fig. 6 FRF measured for the pump unit free support in air

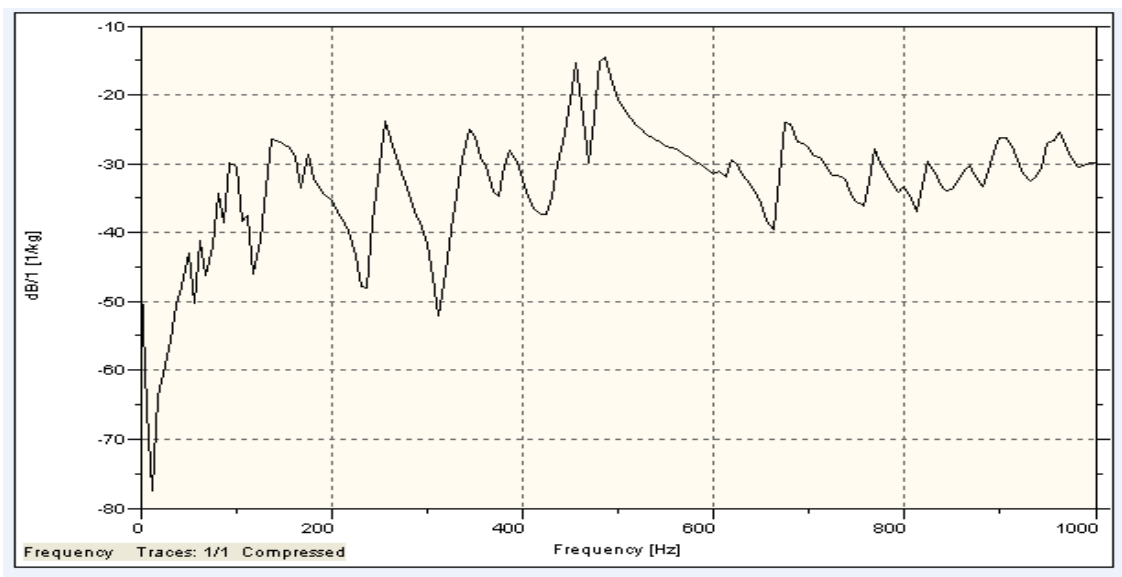

Fig. 7 FRF measured for the pump unit grounded support in water

Modal parameters extracted from FRFs measurements are located in Table 1. The results confirmed that there is a distinct coincidence between the natural frequency and the pump speed at $30 \mathrm{~Hz}$, which indicated that the speed of $30 \mathrm{~Hz}$ is a critical speed. So, operation at resonant frequency generates dangerous vibration level.

The results indicated that the modal frequencies are different for the two cases as shown in Fig. 8. Some modes disappeared or shifted to other values. This is due to the different nature of each case, different fixation, different components, and complexity of the system. Also pumping system consists of many different items of different materials and properties when connected together or joined to other components will result in different dynamic behavior. The excitation at the pump casing will not have the same FRFs characteristics on the pump casing as well as the pipe lines for the above reason. The different components of the system have its separate modal properties called local modes that are when the system is integrated, the modal characteristics will be different from each single item forming global modes which may contain local modes of separate components. 
Table 1 Modal parameters measured from experimental modal testing

\begin{tabular}{|c|c|c|}
\hline \multirow{2}{*}{ Mode No. } & Pump unit freely support in air & Pump unit ground supported in water \\
\cline { 2 - 3 } & Natural frequency $(\mathrm{Hz})$ & Natural frequency (Hz) \\
\hline 1 & 4.9 & 15.24 \\
\hline 2 & 23.80 & 30.0 \\
\hline 3 & 37.70 & 68.40 \\
\hline 4 & 130.12 & 81.20 \\
\hline 5 & 260.60 & 86.0 \\
\hline 6 & 307.22 & 122.40 \\
\hline 7 & 833.51 & 130.0 \\
\hline 8 & 858.57 & 200.0 \\
\hline 9 & 867.54 & 248.50 \\
\hline 10 & 900.18 & 265.36 \\
\hline
\end{tabular}

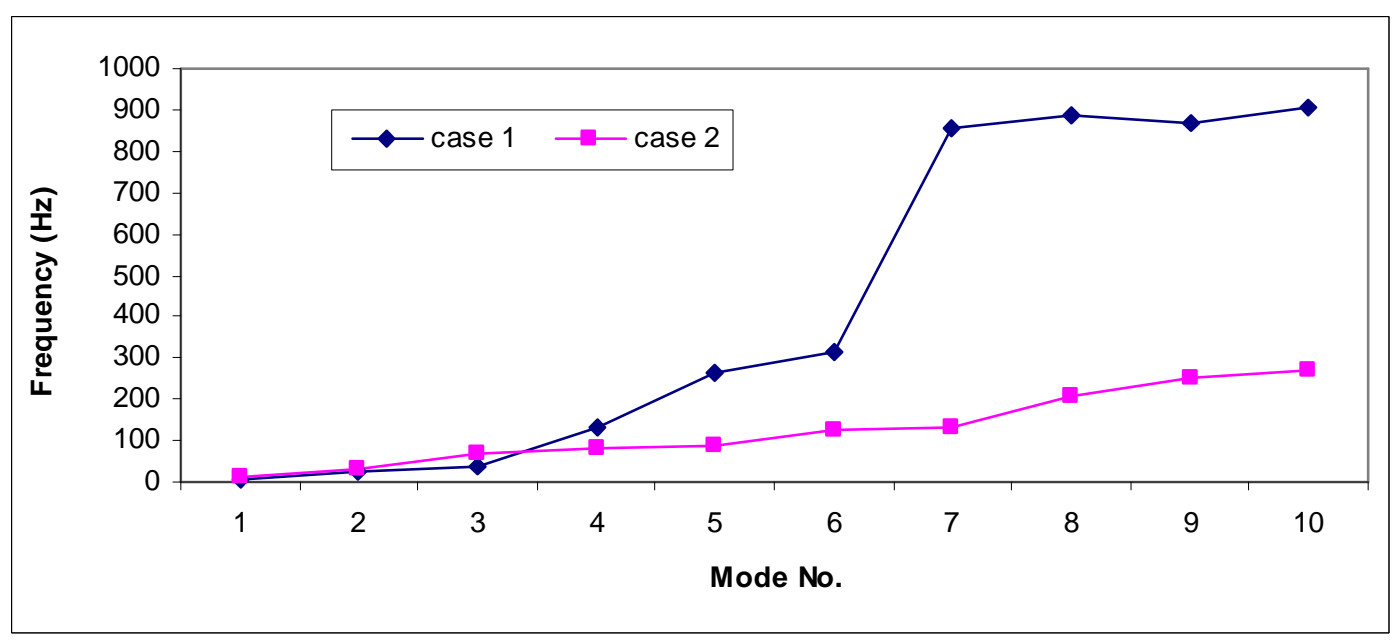

Fig. 8 Measured modal frequency changes for different two cases

Doing modal tests during design phase are very important to make sure that the harmonic and sub- harmonics of the exciting components of the pumping system ( impeller, blades, bearings, rotating speed, etc..) are far from the natural frequencies of the pumping unit. Modal tests in installation phase is very important to make sure that pumping system at this stage is not affected by the nearby machines or facilities to avoid any structural weakness of the pumping unit and supporting foundation. 


\section{OPERATIONAL MODAL ANALYSIS}

Operational modal analysis has a significant advantage over classical modal analysis. Higher estimation accuracy can be obtained by letting the better, spatially distributed, natural load exciting the structure. classical modal analysis using hammer, shaker or multiple shaker excitation, and operational modal analysis based on output-only measurements [9]. For a good simulation, the pumping system is represented by 36 node, 56 line, and 34 surfaces as shown in Fig.9. The measurements were done at speed of $30 \mathrm{~Hz}$ ( $60 \%$ of rating speed) because it is the most serious speed of the system that can cause resonance problem.

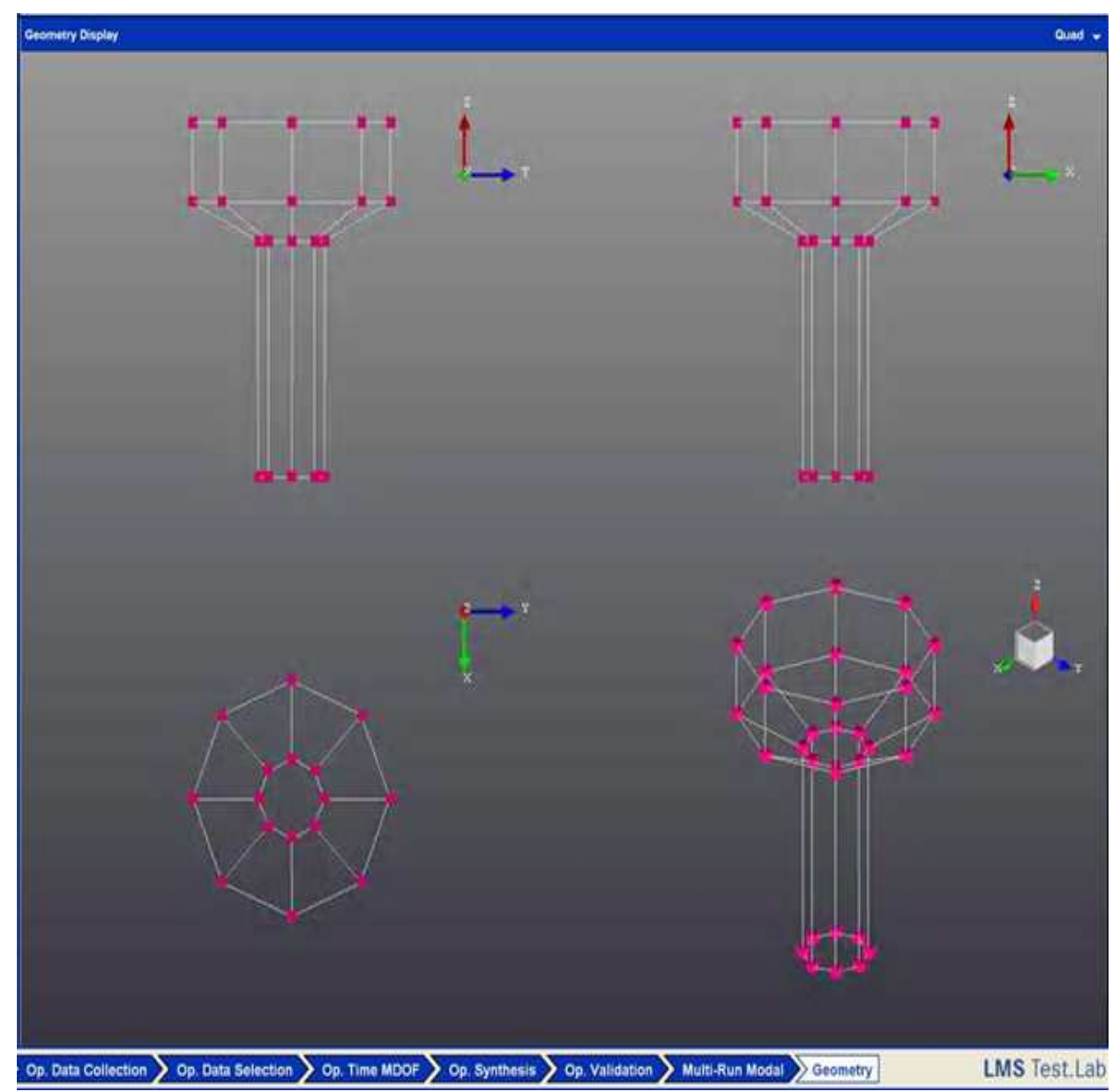

Fig. 9 Pump unit represented as nodes, lines, and surfaces

Table 2 shows the first 7 modes obtained from 8 to $1000 \mathrm{~Hz}$. According to these results it is indicated that the most serious mode shape is at $30.62 \mathrm{~Hz}(66 \%)$ so, it is very important to modify this mode to avoid the problem of resonance. The measured frequency response function FRF is shown in Fig. 10. 
Table 2 Modal parameters measured from operational modal analysis

\begin{tabular}{|c|c|c|}
\hline Mode No & Frequency [Hz] & $\begin{array}{c}\text { Damping Ratio } \\
(\%)\end{array}$ \\
\hline 1 & 3062. & 0.405 \\
\hline 2 & 86.47 & 0.7202 \\
\hline 3 & 89.32 & 0.3155 \\
\hline 4 & 547.1 & 0.5435 \\
\hline 5 & 562.8 & 0.1471 \\
\hline 6 & 879.8 & 0.4224 \\
\hline 7 & 1070 & 0.08212 \\
\hline
\end{tabular}



Fig. 10 Frequency response function of the pumping system at $60 \%$ of rating speed

Figure 11 indicates that the natural modes are extremely different from the natural modes obtained from case of the pump free supported in air and the case of pump grounded in water because of changing of the boundary condition (the pump is operating at speed $30 \mathrm{~Hz}$ ) except at the resonance frequency. The presence of water reduces the natural frequencies and enhances damping. Some modes disappeared and other shifted to other values due to effect of water filling the pumping system. Water 
worked as a natural dashpot which affects the modes and increase damping. Modal tests at actual operation conditions help to solve existing structural problems and modify any future dynamic behavior based on actual operational and fundamental modes.



Fig. 11 Measured modal frequencies change for different three cases

\section{FINITE ELEMENT ANALYSIS}

A 3D finite element (FE) model of the pump unit was built to predict the natural frequencies and mode shapes for the pump unit free support in air, and for the pump is immersed support in water using ANSYS software is shown in Fig.12, 13. The proposed model geometry is in exact dimensions used in the experimental setup. The proposed material models used for the pump model are defined as an isotropic material with young's modulus and poison's ratio value and all of them acts as structural, linear, and elastic materials as shown in Table 3. A free mesh has been used with the element type of SOLID 95. Block lanczos eigenvalue solver is used for solving the model. Results of experimental and analytical modal analysis are shown in Table 4.

Table 3 Material properties

\begin{tabular}{|c|c|c|c|}
\hline properties & Cast iron & Stainless steel & antimony \\
\hline Young's modulus, $(\mathrm{GPa})$ & $2.1 \mathrm{E}+011$ & $2.1 \mathrm{E}+011$ & $6.9 \mathrm{E}+010$ \\
\hline Poisson ratio & 0.3 & 0.3 & 0.3 \\
\hline Density $\left(\mathrm{kg} / \mathrm{m}^{3}\right)$ & 7860 & 8100 & 2710 \\
\hline
\end{tabular}



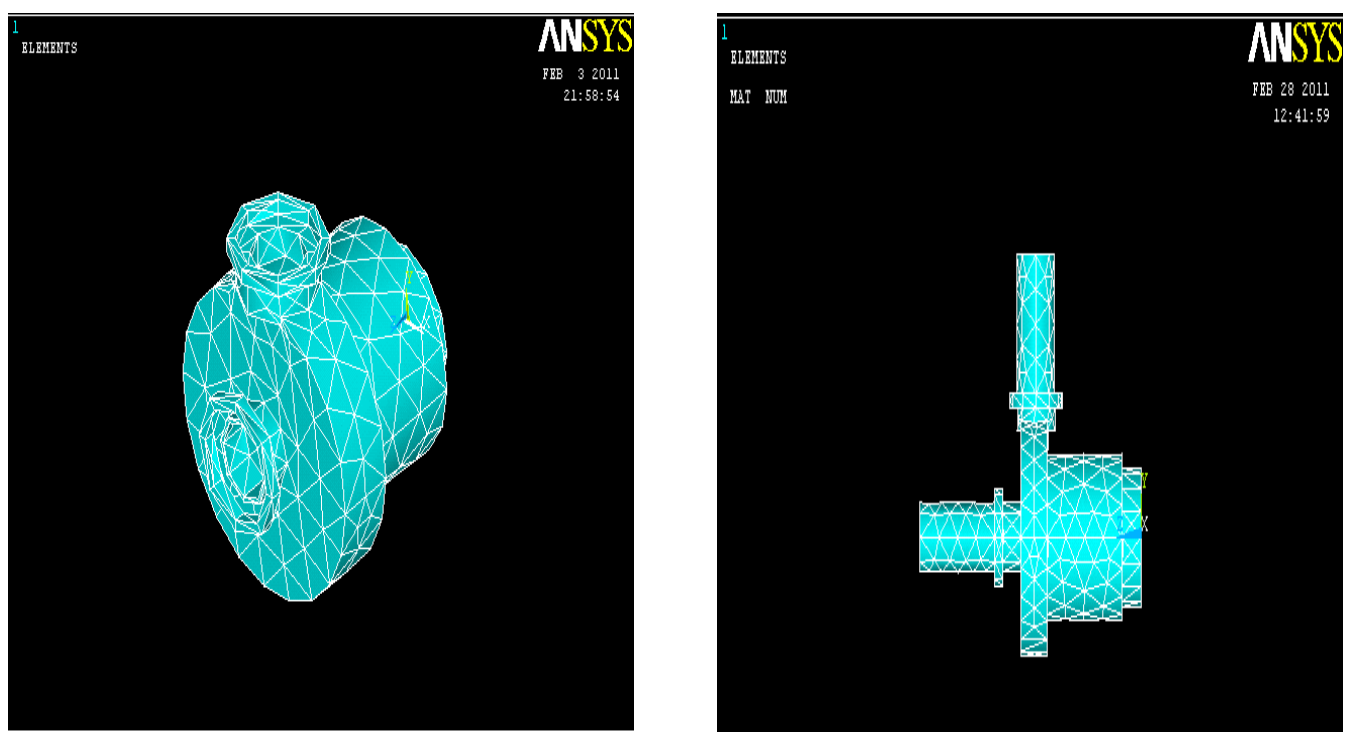

Fig.12 FE model of the pump unit free support in air Fig.13 FE model of the pump unit grounded support in water

Table 4 Correlation between analytical and experimental modal frequencies

\begin{tabular}{|c|c|c||c|c||}
\hline \multirow{2}{*}{ Mode } & \multicolumn{2}{|c|}{$\begin{array}{c}\text { Pump unit free support } \\
\text { in air }\end{array}$} & \multicolumn{2}{c|}{$\begin{array}{c}\text { Pump unit grounded support } \\
\text { in Water }\end{array}$} \\
\cline { 2 - 5 } & analytical & experimental & analytical & experimental \\
\hline 1 & 5.0665 & 4.9 & 15.69 & 15.24 \\
\hline 2 & 24.405 & 23.80 & 31.802 & 30.0 \\
\hline 3 & 38.729 & 37.70 & 70.165 & 68.40 \\
\hline 4 & 133.13 & 130.12 & 84.241 & 81.20 \\
\hline 5 & 267.04 & 260.60 & 87.505 & 86.0 \\
\hline 6 & 314.81 & 307.22 & 125.05 & 122.40 \\
\hline 7 & 854.09 & 833.51 & 134.75 & 130.0 \\
\hline 8 & 886.95 & 865.57 & 207.54 & 200.0 \\
\hline 9 & 870.39 & 858.54 & 251.37 & 248.50 \\
\hline 10 & 907.62 & 882.68 & 268.545 & 265.36 \\
\hline
\end{tabular}

The results showed good correlation between both experimental and analytical analyses for the two cases. Deviation in the order of $2.0 \%$ for the modes of the model free support in air, however, deviation of the FE and experimental results for the pump unit model immersed support in water, is in the order of $3.2 \%$. This minor error is due to nonlinearity of the system, approximation of parameters, and real physical models can not be matched 100\% as shown in Fig. 14. The results show a greet accordance 
between the experimental and analytical models and can be used for further analysis damage detection and structural modification. Both analytical and experimental models were carried out on a pumping system to define a modal model describing the dynamic characteristics of the system. The models are used for understanding of structural characteristics, operating conditions, and performance criteria that enables to design of optimum dynamic behavior or solving structural dynamic problems of the system. The results indicate the importance of doing modal testing in the actual operation and boundary conditions. The dangerous rotating speeds are well determined to avoid operation at resonance condition. The proposed FE model can be used to predict vibration characteristics of variable speed pumping stations under different operating and environmental conditions.

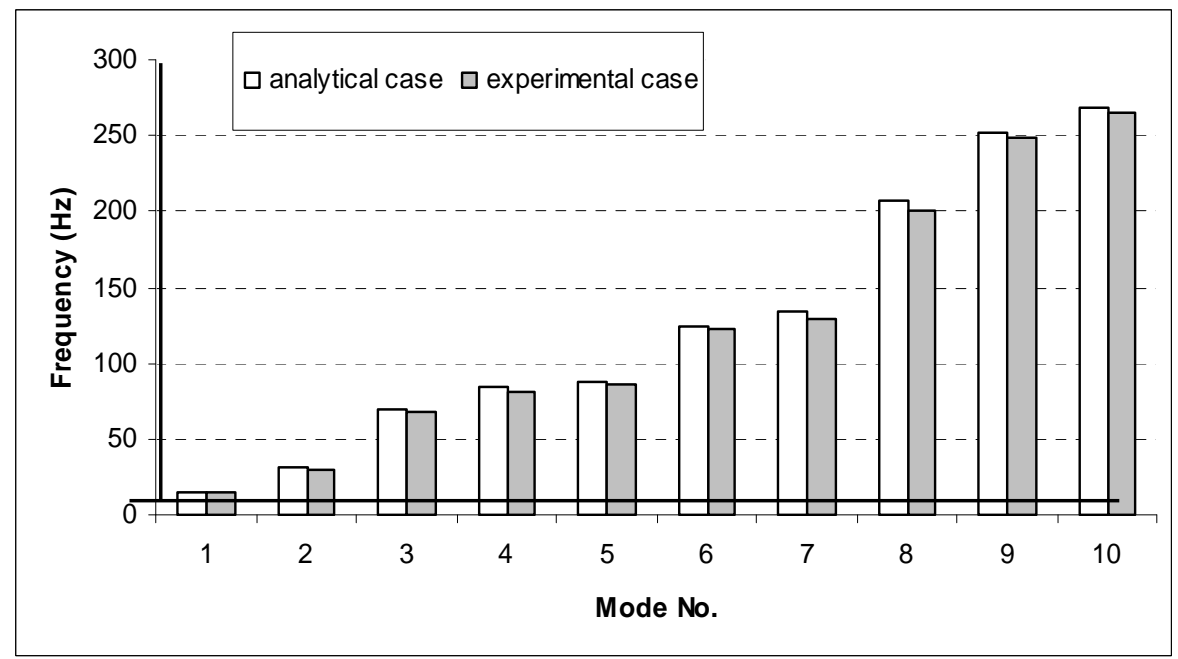

Fig. 14 Correlation between analytical and experimental modal frequencies

\section{CONCLUSION}

- Vibration level increases slightly with increasing the running speed as long as the running speeds are not at resonant frequency.

- It is necessary to do modal analysis at different conditions to predict the dynamic behavior.

- Operating at resonance frequency affects performance and increase vibration level in obviously way.

- The results indicate that resonance is a major problem that can be encountered in variable speed pumps.

- Natural frequencies obtained from experimental modal testing are extremely different from that obtained from operational modal analysis.

- It is important to evaluate the dynamic behavior of variable speed pumps and determine the dangerous operating frequencies to avoid occurring of mechanical problems such as resonance.

- Yet, while variable speed drives clearly offer versatility to the pumping industry and cost savings to the consumer, they also present some difficult engineering challenges for both suppliers and users particularly in the area of vibration. 


\section{REFERENCES}

1. Stefan M. Abelin, "Improving Pumping System Performance", A sourcebook for Industry, U.S. Department of Energy's Industrial Technologies Program (ITP) and the Hydraulic Institute (HI), 2006.

2. Europump and hydraulic institute. "Variable Speed Pumping - A Guide to Successful Applications." Elsevier advanced technology, Oxford, ISBN 1880952- 58- 0, 2004.

3. Abu-Zeid, M. A., "Performance Analysis of Adjustable-Speed Pumping Units", PhD Dissertation, Faulty of Eng., Al-Azhar University, 2002.

4. Sanders, D., Expert Systems for Diagnosis and Performance of Centrifugal Pumps, A Finnish Technical Research Center report entitled, Metcam Inc.February, 2008.

5. www. Bpma.org.uk, Variable speed driven pumps: best practices, British Pump Manufacturers Association, Birmingham, England, 2010.

6. Abdel-Rahman, S. M., and El-Shaikh, S. A., Diagnosis Vibration problems of Pumping Stations: Case Studies, $13^{\text {th }}$ International Water Technology Conference, IWTC, Egypt, 12-15 March 2009.

7. Boyadjis, P., Detecting a hidden lateral rotor natural frequency in a sewage pump, www. Pump- Zone. com, Pumps \& Systems, June 2004.

8. Bruel\&kjaer, machine condition monitoring, Application Note BR 0267-13, B\&K, Denmark,1989.

9. DeMatteo, T., Operational Deflection Shape and Modal Analysis Testing To Solve Resonance Problems, Consultant Emerson Process Management / CSI Division, 2001).

\section{تحليل الاهتزازات لمنظومـة الطلمبات متغيرة السرعة}

إن استخدام الدحركات متغيرة السرعة من أفضل الوسائل الاقتصادية لتحسين أداء طلمبات رفع المياه لها لها

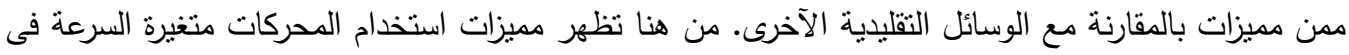
تتشغيل الطلمبات حيث انها تؤدى الى تحسين اداء هذة الطلمبات وتسمح لها بان تعمل عند اقصى كفاءة مدكنة مما يؤدى الى تقليل الفقد فى الطاقة وبالتالى تقليل تكاليف التشغيل. حتى الان وبالرغم من كل مميزات الدحركات

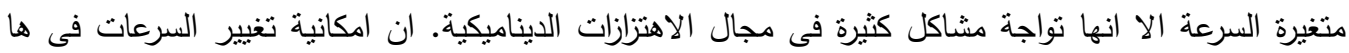
النوع من الطلمبات يؤدى الى زيادة فرصة حدوث توافق بين سرعات التشغيل والسرعات الحرجة. فعندما تتغير

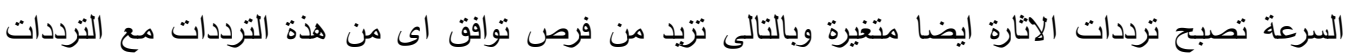

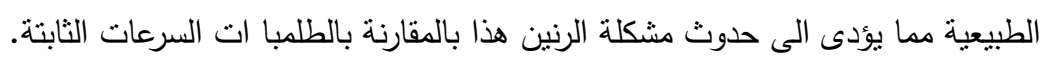

لهذة الاسباب فان هذة الدراسة قد خصصت لعمل مخطط مناسب لفحص وتحليل الاداء الديناميكى للطلمبات

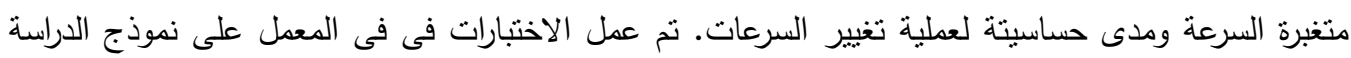
المكون من طلمبة طاردة مركزية تعمل بمحرك متغيير السرعة بقدرة 5 كيلو وات وعدد لفات 3000 لفة/دقيقة. نم 
اختيار مدى من السرعات يتراوح من 25 هيرتز حتى 50 هيرتز • نم قياس الاهتزازة القسرية عند مدى مختلف من هن

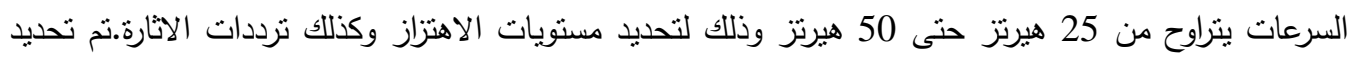

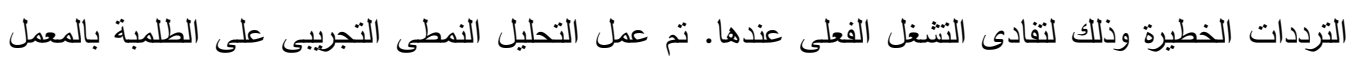
عند مراحل التصميم والتركيب وذلك لتقدير الحالة الديناميكية للمضخة عند الظروف المختلفة. ولقد تم ايضا عمل على على على التحليل النمطى التشغيلى للمضخة وذلك لتحديد الحالة الديناميكية لها عند الظروف الفعلية للتشغيل. وقد اثنارت النتائج المعملية ان الخصائص الديناميكية تتغير فى المراحل المختلفة للتصميم والتركيب والتشغيل مما يؤكد ضرورة عمل التحليل النمطى عند الظروف المختلفة لامكانية التحكم فى السلوك الديناميكى ومستوى الاهنزازة. تم بناء نموذج رياضى باستخدام طريقة العناصر المحددة وذلك لتحديد الخصائص الديناميكية للمضخة نظريا وقد تم حل هذا النموذج باستخدام حزمة البرامج التى تعمل على منظومة الحاسب الالىى. وقد اظهرت النتائج وجود بأن ارتباط جيد بين النموذج الرياضى والنتائج المعملية. 